\title{
CONSTITUCIONALISMO Y EXPERIENCIA POLÍTICO-JURÍDICA
}

\author{
POR \\ Danilo Castellano (*)
}

\section{1. ¿De qué hablamos?}

Se dice que el lenguaje es el "lugar" del pensamiento. Pero si el pensamiento no es la aprehensión de lo real difícilmente puede ser su "lugar". Si, como ocurre cada más frecuentemente, el pensamiento pretende ser tal porque pensamiento de una ideología (que, en último término, es el intento de interpretar la realidad sobreponiéndose a ella), entonces aquél no puede tener un solo "lugar", sino que tendrá tantos, separados y cerrados, cuantos son las ideologías. Es por lo mismo que actualmente se usan a menudo las mismas palabras, pero no se dicen casi nunca las mismas cosas.

La observación sirve también para el término constitucionalismo e incluso para el de Constitución. Constitucionalismo y Constitución, de hecho, se usan con una pluralidad de significados. Los iuspositivistas consideran generalmente que la Constitución es un conjunto de reglas, puestas convencionalmente como fundamentales, que dan identidad a un ordenamiento (1). La Constitución sería, por tanto, la ley fundamental. Carl Schmitt, positivista, pero positivista problemático, observa -sin embargo- que este es el último y el menos importante de los significados del término Constitución (2). Y no hablemos del significado que la misma

(*) Traducción de M. A. (Nota de la R.).

(1) Cfr. A. BARBERA, "Le basi filosofiche del Costituzionalismo", en AA.VV., Le basi filosofiche del Costituzionalismo, Roma-Bari, Laterza, 1997, 1998², pág. 3.

(2) Cfr. C. SCHMITT, Verfassungslehre, Berlín, Duncker \& Humblot, 1928. 
tiene, por ejemplo, para De Maistre (3), y para otros muchos autores que desde el fin de la antigüedad han estudiado el problema político-jurídico con método realista. Pero los mismos iuspositivistas han de observar finalmente que el constitucionalismo "es un movimiento político, filosófico y cultural volcado a la conquista de documentos constitucionales marcados por los principios liberales o demo-liberales" (4). Así pues, el constitucionalismo sería la forma jurídica que debe asumir la doctrina política liberal. Por ello el constitucionalismo puede considerarse preñado de significado sólo si y en la medida en que se refiere a lo que algunos juristas llaman el orden de valores constitucionales. En otras palabras, el constitucionalismo es la doctrina de la Constitución liberal. Por ello es el presupuesto de lo que actualmente se entiende como Constitución, lo que la trasciende y pretende fundarla.

\section{Significado del liberalismo.}

Así circunscrito, el constitucionalismo es la doctrina que separa política y moral, Estado e Iglesia. Es la doctrina que funda el ordenamiento jurídico sobre la soberanía, esto es, en última instancia sobre el poder que no es ni poder jurídico ni poder político, porque pretende ser su condición y fundamento. Es la doctrina que "tutela" los derechos del hombre -tal y como se entienden por la modernidad (5) - en cuanto asume y reivindica la libertad como "libertad negativa", esto es, como libertad ejercitada con el solo criterio de la libertad, o sea, la libertad sin ningún criterio. Es la doctrina que sueña "controlar" el ejercicio del poder con la técnica de su división y "separación” geográfica. Es la doctrina que pone la garantía de los derechos, reducidos (coherente aunque absurdamente) a facultates agendi basados sobre las normae agendi, en la ley como simple decisión o mandato procedimentalmente correctos: el llamado "Estado de derecho" que identifica erróneamente el dere-

(3) Cfr, J. DE MAISTRE, Saggio sul principio generatore delle costituzioni politiche $e$ delle altre istituzioni umane, Milán, Scheiwiller, 1975.

(4) A. BARBERA, op. cit., pág. 3.

(5) Se reenvía, para este tema, a D. CASTELLANO, Razionalismo e diritti umani, Turín, Giappichelli, 2003. 
cho con la norma positiva, ésta a su vez mucho menos que la misma ley.

El constitucionalismo se presenta, así, bajo muchas formas: jacobina, liberal en sentido anglosajón, radical-democrática, "católico-liberal" e incluso estatalista, aunque esta última pueda parecer a primera vista una afirmación contradictoria e insostenible: Hegel, de hecho, sostiene el Estado totalitario, al que -en cambio- reconoce y asigna el ejercicio de la "libertad negativa" liberal.

Su fenomenología multiforme no debe llevarnos a engaño. Uno de los mayores historiadores del liberalismo europeo, Guido De Ruggiero, ha escrito con razón que la Declaración de los derechos es la matriz de tres revoluciones, "una revolución liberal, stricto sensu, una revolución democrática y una revolución social": "Pero las tres no representan sino la expansión progresiva de un mismo espíritu individualista, llevado hasta la exasperación extrema del socialismo, de modo que todas entran por igual en la historia de la mentalidad liberal" (6). En la base del constitucionalismo hay, por tanto, un mínimo común denominador: el racionalismo individual, político y social (7), que es la esencia del la doctrina liberal.

\section{La historia del constitucionalismo como el seguimiento de la utopía.}

No hay duda de que la historia moderna y contemporánea, sobre todo la occidental, pero ahora parece que también la oriental, está caracterizada por el intento de instaurar primero y de reformar después el constitucionalismo. Es la epifanía del reformismo de una revolución (y por lo mismo revolución él mismo), porque viene caracterizada de una carrera continua hacia la innovación como reparación de lo que "no va bien". Es decir, es la búsqueda permanente de remedios a la insuficiencia y a los errores causados progresivamente por los variados modelos propuestos por el constitucionalismo a través de la Constitución. La época de las revo -

(6) G. DE RUGGIERO, Storia del Liberalismo europeo, Bari, Laterza, 1925, 1959 (6a ed.), pág. 76.

(7) Cfr. F. SARDÁ y SALVANY, El Liberalismo es pecado, pág. 9. 
luciones (gloriosas y no tanto, americana y francesa) ha sido la estación de la gran ilusión según la cual la Constitución como "documento" -por usar la expresión de Augusto Barbera- habría representado la garantía "política" del ejercicio del derecho de "libertad negativa", fuese considerada como garantía de igualdad (doctrina liberal stricto sensu), o exigiese una igualdad sustancial (doctrina marxista). Lo que resalta es que para el constitucionalismo rige la afirmación explícita y clara de la Asamblea legislativa francesa de 26 de agosto de 1789: "Toute société dans laquelle la garantie des droits n'est pas assurée, ni la séparation des pouvoirs determinée, n'a point de Constitution" (artículo 16 de la Declaración de los derechos del hombre y del ciudadano). Dejando por el momento la gran cuestión de la naturaleza de los derechos, no hay duda de que la Constitución se reduce aquí a un mero instrumento de "garantía", que se piensa pueda ser tal sólo si hay separación formal de los poderes. Ha de observarse, sin embargo, que la concepción de Montesquieu de la división de poderes lleva a la "limitación" del poder pero no a su intrínseca regulación. La frontera entre los poderes es "geográfica" como "geográfico" viene a ser -lo veremos dentro de poco- el derecho: el poder es así, y no podría ser de otro modo, necesaria e intrínsecamente no regulado, porque se tuviese una naturaleza distinta del solo poder sería un poder "calificado" por el adjetivo que lo acompaña: político, moral, jurídico, religioso, potestativo, real, etc. Su calificación, dictada por su naturaleza, vendría a ser el criterio intrínseco y legitimaría también su ejercicio. Pero esto representaría la refutación radical de la "libertad negativa" sobre la que se apoya la doctrina liberal y de la que ha hecho su esencia.

\section{Exigencias verdaderas y respuestas falsas.}

Que el ejercicio del poder requiere que esté regulado es una exigencia justa y racional, se trate de los llamados -con definición convencional y absolutamente infundada- "poder público" o "poder privado". A tal fin es, sin embargo, totalmente inidóneo, aunque no totalmente inútil, el "control" externo, incluso cuando se ejercita a 
través de la ley (positiva), considerada como puro mandato del soberano (voluntad del Estado, del pueblo o de la mayoría contingente), acompañado de la efectividad. La ley, de hecho, para ser verdaderamente tal, debe "penetrar" la naturaleza de las cosas y no puede ignorarla. El gran iuspublicista italiano Vittorio Emanuele Orlando subrayó, por ejemplo, la absurda pretensión de Napoleón de definir la donación como "acto" en lugar de "contrato", aunque a esta exigencia del entonces "poder político" se plegaron inmediatamente diversos "juristas" franceses (8). Por otra parte, para limitarnos a un segundo ejemplo, el poder moral y jurídico de la "patria potestad" no es un poder arbitrario: no lo es ni en su definición, y por lo que toca a su recepción en el derecho positivo, esto es por el legislador; ni en su ejercicio, esto es, por parte de los padres. Lo que regula intrínsecamente es el bien del menor, que debe ser ayudado a crecer y madurar respetando y de conformidad con su naturaleza humana.

El derecho debe ciertamente tutelar la libertad, pero para hacerlo no puede asumirla como "negativà. Si hiciese esto estaría negándose, al menos parcialmente: el derecho sería entonces inevitablemente "límite" de la libertad en vez de su potenciación. La "cosa" es particularmente evidente en el campo del derecho público, que si fuese llamado a tutelar la "libertad negativa" se estaría convirtiendo en último término en garante de la anarquía. Algunos ordenamientos jurídicos, que han acogido sustancialmente esta ratio, se han encontrado después ante aporías, esto es, callejones sin salida. Bastaría pensar, por poner un solo ejemplo, en la objeción de conciencia, que no es la objeción de la conciencia (9), y que -reconocida como derecho subjetivo inalienable en el plano del derecho constitucional- queda reducida a la nada cuando, por ejemplo, el Estado no está en condiciones de prestar a nivel sanitario la práctica solicitada del aborto procurado (considerado necesario para la salud de la gestante). El ordenamiento jurídico italiano, por ejemplo, cae

(8) Cfr. V. E. ORLANDO, "Discorso all'Assemblea Costituente del 10 marzo 1947”, en La Costituzione della Repubblica nei lavori preparatori dell'Assemblea Costituente, vol. I, Roma, Camera dei Deputati-Segretariato Generale, 1970, pág. 298.

(9) Véase sobre el asunto D. CASTELLANO, "Obiezione di coscienza e pensiero católico", ahora en ID., La razionalità della politica, Nápoles, Edizioni Scientifiche Italiane, 1993, págs. 25-44. 
en esta contradicción radical e insuperable (cfr. Ley 194/1978), porque de una parte ancla la objeción de conciencia en el (considerado) derecho a la coherencia subjetiva, mientras que de otra se empeña en garantizar la práctica una opción (también subjetiva y considerada derecho subjetivo) como la del aborto procurado, sobre todo si éste viene invocado por razones de salud de la gestante, quien en realidad siempre está en la condición de poder invocarlo, en cuanto la salud -según la previsión de la ley-viene referida a ámbitos amplísimos, y no sólo a la salud del cuerpo sino también a aspectos psicológicos considerados lato sensu. Pero no solo. Algún ordenamiento jurídico (de nuevo el italiano, por ejemplo) permite dar a luz de incógnito. La norma de dicho ordenamiento jurídico (cfr. Decreto de la Presidencia de la República 396/2000), originada por una finalidad digna de ser apreciada, cual concebir el nacimiento del concebido cuya vida la madre habría suprimido invocando la ley del aborto procurado, ¿qué derecho tutela? Con seguridad el de la madre de liberarse de todas las obligaciones naturales y deberes positivos ligadas al hecho de la concepción y nacimiento del hijo. Se niega que del hecho nazca el derecho. Ya no sería válido, pues, el brocardo según el cual ex facto oritur ius. Por esto no resaltan los derechos del hijo, que -aunque dado o adoptado- no viene a encontrarse en la condición de la inmensa mayoría de los legítimos. El citado Decreto 396/2000 tutela, sí, la "libertad negativa" de la madre, pero para hacerlo debe desconocer el derecho del hijo a ver cumplidas las obligaciones naturales de sus progenitores respecto de él. El derecho concluye, así, por negar su naturaleza y su función. La heterogénesis de los fines que originan los derechos humanos y el constitucionalismo (entendido, según hemos dicho, como "movimiento volcado a la conquista de documentos constitucionales marcados por principios liberales o demoliberales"), y que hemos ejemplificado brevemente, demuestra que el constitucionalismo, a través de las constituciones liberales o demoliberales, no puede responder a las verdaderas exigencias que pone la experiencia político-jurídica. No puede hacerlo a causa de su racionalismo, que (siendo una forma positiva del nihilismo) queda como respuesta irracional y por lo mismo errónea respecto de las instancias de la justicia que comprende también el valor de la libertad y el deber/derecho de la misma. 


\section{Las razones por las que el constitucionalismo es un problema para la experiencia político-jurídica.}

El ya citado Vittorio Emmanuel Orlando, "liberal”, observó (y es significativo que lo hiciera en sede de la discusión general sobre el proyecto de Constitución italiana) que "las Constituciones las hacen más las costumbres y los modos de su actuación que la fría redacción de sus artículos" (10).

Esta vía histórico-pragmática, en cambio, no se considera (ni menos aún acoge) por el racionalismo del constitucionalismo, que en cambio prefiere insistir sobre los "artículos" para imponer en cambio que, a veces, es una revolución. Por ello el constitucionalismo privilegia en las constituciones más la parte dedicada a los principios sobre los que deben basarse que la dedicada a la organización del Estado. La Constitución, de hecho, se entiende por el constitucionalismo como un instrumento para imponer rápidamente la realización de un modelo de sociedad elaborado sobre la base de una ideología.

El constructivismo político, aunque como es sabido no se identifique tout court con el constitucionalismo, le ha dado una forma manifiesta. Aquél -como subrayó, por ejemplo, el maestro de Bobbio, Gioele Solari (11)- ha creído poder transformar lo político en constitucional. En otras palabras, el pacto social, que es asunción hipotética absolutamente irreal, cuyo contenido se recoge y documenta en la Constitución, firmaría el nacimiento de la sociedad política. Ésta, no existiendo antes del pacto, y por tanto teniendo una génesis voluntarista, no sería natural ni estaría naturalmente ordenada a las exigencias de la naturaleza del hombre. Por el contrario, no estando naturalmente regulada, sería plasmable por la voluntad de los consociados como en una sociedad por acciones. Para el constructivismo el constitucionalismo coincide con el ordenamiento jurídico constitucional, que crea y garantiza los derechos fundamentales, definidos a menudo como inviolables, y por eso fija

(10) Cfr. V. E. ORLANDO, loc. cit., pág. 288.

(11) Cfr. G. SOLARI, La formazione storica e filosofica dello Stato moderno, Turín, Giappichelli, 1962, en particular pág. 65. 
también la frontera entre Estado y ciudadanos. El constitucionalismo del constructivismo político, por tanto, asume la libertad como "libertad negativa" (la que Hobbes - por ejemplo- llamaba libertad natural); considera que el poder político se identifica con el poder y que, por tanto, sea un mal, aunque no podamos liberarnos de él (es la tesis, por ejemplo, de la Harendt); funda el derecho, y en particular el público, sobre la soberanía, entendida filosóficamente, y por eso -una vez más- recurre al poder no calificado para intentar fundar el derecho, justificado solamente en cuanto instrumento de una finalidad convencional asignada por el Estado (12).

Otra forma, aparentemente, pero sólo aparentemente, más "realista" y menos "abstracta", a través de la cual el constitucionalismo se hace instrumento para la realización de un modelo ideológico de sociedad, es la "politología, que se presenta como "nueva ciencia" política, cuyo gnosticismo ha sido ilustrado en parte por Voegelin (13). También ella, en última instancia, hace del poder el fundamento del poder político que, de manera elástica y dinámica, da contenidos siempre diversos al ordenamiento jurídico, también al constitucional.

(12) Para las características del Estado moderno y del constitucionalismo, en los aspectos descriptivos, puede verse entre una vasta bibliografía N. MATTEUCCI, Lo Stato moderno, Bolonia, Il Mulino, 1993, $1997^{2}$ (que defiende y se adhiere a las razones del constitucionalismo y del Estado moderno), y en sentido problemático M. AYUSO, ¿Después del Leviatán? Sobre el Estado y su signo, Madrid, Speiro,1996, Dykinson, $1998^{2}$ [quien, en otra obra, pone en discusión también la validez de la teoría de la división de poderes, que considera -fundadamente- una aproximación meramente técnica y, por ello, inadecuada, a las grandes cuestiones que pone el derecho público (cfr. La cabeza de la gorgona, Buenos Aires, Ediciones Nueva Hispanidad, 2001, sobre todo págs. 37 sigs.)]. Debe registrarse aquí también la tesis según la cual la constitución sería "vía" para la recuperación de la forma "mixta" de gobierno (al menos bajo el aspecto formal), después de la experiencia absolutista y después de la experiencia jacobino-radical [la primera basada en la voluntad del soberano (soberanía del Estado), la segunda sobre la voluntad popular (soberanía del pueblo). Para la descripción de esta tesis, véase entre otros M. FIORAVANTI, Costituzione, Bolonia, Il Mulino, 1999]. La interpretación del constitucionalismo como garantía y defensa contra la "soberanía", sostenida en ocasión las revoluciones con fuerza y repetidamente por la escuela liberal, no parece sostenible. La experiencia jurídica contemporánea, en efecto, demuestra lo contrario: de una parte, la constitución con frecuencia ha sido instrumento de la revolución (y no "defensa" frente a ella); de otra, la constitución ha sido (y es) la "vía" a través de la que la soberanía del pueblo realiza su propia voluntad. A este propósito bastaría considerar, por ejemplo, lo que establece la Constitución española de 1978.

(13) Cfr. E. VOEGELIN, The new science of politics, Chicago, The University of Chicago Press, 1952. 
El orden jurídico coincide y debe coincidir con el orden sociológico efectivo, que es la representación del modo de ser, contingente y a veces efímero, de la sociedad definida "civil". El constitucionalismo se refleja en la Constitución, que a su vez es espejo de la sociedad. ¿Puede, sin embargo, un ordenamiento jurídico, y en particular un ordenamiento constitucional, basarse sobre las representaciones del orden sociológico? En otras palabras, ¿puede el derecho tener como fundamento una verdad constituida como tal porque "compartida" $y$, en cuanto compartida, por lo menos mayoritariamente, impuesta a la sociedad como norma por la misma sociedad o por los componentes sociales mayoritarios o hegemónicos. Es el problema del republicanis mo global contemporáneo, que entiende el orden constitucional como una construcción necesaria e ineludible, pero que se puede componer y descomponer a voluntad. Éste radicaliza, así, de una parte, las premisas de la doctrina politológica y, de otra, busca ennoblecer lo que no puede serlo: el mero poder, de hecho, es tal y tal queda, $y$-aunque se use con las armas con que la naturaleza ha dotado al hombre- permanece brutal mientras no sea regulado por criterios intrínsecos, fundados sobre la naturaleza de las "cosas", que la inteligencia humana está llamada a "acoger" (14).

\section{Conclusión.}

El constitucionalismo nace y se mueve dentro de la esfera de una visión pesimista del hombre, aunque los remedios que pro p o ne y las soluciones político-jurídicas que indica sean intentos optimistas (a veces ingenuos) de soluciones de las cuestiones fundamentales de la política y el derecho.

En sede conclusiva debe notarse que el racionalismo que lo caracteriza no le permite dar respuestas sino desde el interior del sistema asumido. Estas, por lo mismo, pueden ser coherentes, pero no son necesariamente fundadas, $\mathrm{y}$-como hemos apuntado- se han revela-

(14) Aristóteles observa justamente que lo esencial para afrontar la cuestión de la comunidad y de su ordenamiento jurídico es que el Estado debe encontrar su fundamento teorético para legitimar el "mando" político, que es mando de hombres libres e iguales a hombres también libres e iguales (cfr. ARISTÓTELES, Política, respectivamente I, 1253a e III, 1277b). 
do inidóneas para la misma solución del problema que el constitucionalismo pretendía resolver. Lo que revela que el constitucionalismo renuncia (más aún, está obligado a renunciar) a preguntarse sobre la cuestión del poder, que es la cuestión de las cuestiones de la política y el derecho público. El constitucionalismo, así, la reputa resuelta a priori por el consentimiento, aunque éste se entienda como adhesión a un proyecto cualquiera. Lo re vela la manera con que plantea el problema del "poder constituyente", que no es considerado simplemente ordenador (lo e implicaría sobre todo el conocimiento de la naturaleza y de los fines de la comunidad política) sino constitutivo del orden jurídico de la sociedad y, por tanto, de la sociedad política en sí. No por casualidad se ha escrito que la Constitución es la puerta a través de la cual el momento abstracto del Estado entra en la vida y en la realidad (15). El Estado, por ello, se identifica con su ordenamiento jurídico, entendido como institución.

El renacimiento del derecho internacional, producido después de la segunda guerra mundial, y la globalización en acto, de una parte, y la afirmación de la doctrina politológica, de otra, han puesto en crisis la vieja doctrina del constitucionalismo: el ordenamiento jurídico (incluso considerado como "cerrado") ya no es la condición del derecho.

Entendámonos. Algunas de las exigencias que pone el constitucionalismo son verdaderas. Ya lo hemos reconocido. Lo que, en cambio, se revela inaceptable es la solución que el constitucionalismo ofrece sobre la base de premisas igualmente inaceptables, en primer lugar por convencionales. Inaceptable es también la principal función que aquél asigna al ordenamiento jurídico, a veces en abierto contraste con la tradición del derecho civil y penal, que también es parte, aunque se considere que subordinada a la Constitución, del ordenamiento jurídico. Lo que es confirmación ulterior de su racionalismo, que "pliega" la justicia a las pretensiones de la ideología que domina el constitucionalismo y que se "concreta" en las Constituciones modernas.

(15) Cfr. G.W.F. HEGEL, Verlesungen über die Philosophie der Geschichte, trad. it., vol. I, Florencia, La Nuova Italia, 1941, 1967², pág. 138. Para el constitucionalismo hegeliano lo relevante no es tanto la defensa de los derechos de la persona (vista como un accidente), considerados inexistentes antes del derecho del Estado, cuanto el problema de la consecución más segura posible de los fines del Estado. La tesis ha sido divulgada por distintos juristas positivos, entre los que destaca Santi Romano. 